\title{
Extraction of fresh banana waste juice as non-cellulosic and non-food renewable feedstock for direct lipase production
}

\begin{abstract}
The bulk availability of banana waste in the world has made a move towards the development of alternative novel renewable sugars in present study as the pressed juice from banana frond and pseudostem was found to contain high level of renewable sugars such as glucose, sucrose and fructose. By using a simple sugarcane press, the glucose content in the banana frond juice was $16.6 \mathrm{~g} / \mathrm{L}$, which accounts for $55 \%$ of the total fermentable sugars. From the results, the lipase production reached $\sim 200 \mathrm{U} / \mathrm{mL}$ in medium comprising banana frond juice and banana pseudostem juice, comparable to basal medium with glucose $(206.3 \mathrm{U} / \mathrm{mL})$ as carbon source in basal media. As banana pseudostem possesses high content of starch, microwave heating pretreatment showed $36 \%$ enhancement of glucose content $(10.4 \mathrm{~g} / \mathrm{L})$ in juice as compared to direct pressed juice $(7.78 \mathrm{~g} / \mathrm{L})$. This result indicates that banana waste juice can be used as an alternative fermentable carbon source for lipase production and has potential as a fermentable carbon source.
\end{abstract}

Keyword: Direct pressing; Fermentable sugars; Banana waste juice; Lipase; Microwave 